\title{
Research in Family/General Practice is Essential for Improving Health Globally
}

\author{
Walter W. Rosser, MD, CCFP, FCFP, MRCGP, Guest Editor (UK) ${ }^{1}$ \\ Chris van Weel, MD, PhD, FRCGP, Guest Editor ${ }^{2}$ \\ ${ }^{1}$ Department of Family Medicine, Queens University, Kingston, Ontario, Canada \\ ${ }^{2}$ Department of General Practice, University Medical Center Nijmegen, Nijmegen, The Netherlands \\ Ann Fam Med 2004;2:S2-S4. DOI: 10.1370/afm. 145.
}

$\mathrm{D}$ uring the last decade of the $20^{\text {th }}$ century, there has been an increased recognition by the World Health Organization of the importance of primary care in improving the health of populations, with the medical literature providing supporting evidence. Under the influence of this growing awareness, many developed and developing countries have bolstered the role of primary care in the organization and structure of their health care systems. ${ }^{1-3}$ Numerous universities in these countries have increased the primary care focus and content of their educational programs to better address the primary care needs of the populations their graduates will serve. This increasing interest in the provision of primary health care clinical service and education, however, has not been accompanied by investment in research efforts.

Primary care research is the missing link in the development of high-quality, evidence-based health care for populations. Awareness of the missed potential to benefit the health of the world's population led to the World Organization of Family Doctors (Wonca), supported by a number of other agencies (see sponsors list), to underwrite an invitational conference on the future of primary care research. Under the title Improving Health Globally: The Necessity of Family Medicine Research, 74 primary care experts from 34 countries

Conflict of interest: none reported

\section{CORRESPONDING AUTHOR}

Walter Rosser, MD, CCFP, FCFP, MRCGP(UK)

Department of Family Medicine

Queens University

220 Bagot St

Kingston, Ontario, Canada K7L 5E9

rosserw@post.queensu.ca met between March 8 and 11, 2003, at Queens University in Kingston, Ontario, Canada. The participants were asked to develop recommendations on how to better realize the potential of family medicinefamily/general practice (from here on family medicine) research. Details of the organization and process of the conference are outlined elsewhere. ${ }^{4}$ The conclusions and recommendations of the conference are presented in this supplement. The focus of this conference was on research in family medicine.

The conference spent time defining the domain of family medicine as a discipline and thus the domain of family medicine research, as family physicians/general practitioners (from here on FPs) work in close contact with all medical specialties. A vigorous discussion led to the conclusion that family medicine is a well-defined discipline in which research in the context of primary care is essential to guide FPs in appropriate clinical decision making. Barbara Starfield's work linking the strength of the primary care sector in many countries with improved health status of the population strengthened the resolve of the group of the need for family medicine research. ${ }^{5}$

Emerging from this discussion was the need for the discipline to be more proactive in clearly defining the discipline of family medicine and assisting our colleagues, policy makers, educators, and funding agencies to understand why research in the primary care context is essential for improving any nation's health. These statements are supported by research results that have emerged from studies on common problems and their optimum management. Knowledge gained from this research can be applied in any country, resulting in improved quality of health care and often reducing use of expensive therapy. ${ }^{6-10}$ Often the more common the problem, the less it is researched, creat- 
ing considerable deficiencies in knowledge for practicing FPs. ${ }^{11}$

Evidence emerged that the greatest potential for improving population health can be found in the application of simple research principles in the most underdeveloped and underresourced health care systems. ${ }^{12,13}$ Being more proactive about these facts should make the discipline more attractive as a career choice for medical students who are unaware of the potential power and intellectual demands of research at the primary care level.

During the conference views from those outside the family medicine research community were sought. Richard Horton challenged the conference participants to be less introspective and to begin to challenge the status quo and gain acceptance of our convictions about the value of our research. ${ }^{14}$

A brainstorming session on how to build research capacity identified the need for our world organization, Wonca, to assume the role of providing an information clearinghouse so ideas could be shared internationally. Some topics in which sharing information was considered of particular value included capacity building, ${ }_{1}{ }^{15}$ models of mentoring, ${ }^{14(\mathrm{p} 13)}$ research methods for clinical research ${ }_{1}^{16}$ knowledge transfer, ${ }^{17}$ and problem solving for undifferentiated clinical problems. ${ }^{8,18}$ International information sharing would allow a free exchange of ideas and provide support for the adaptation of new research findings between countries with different health care systems.

The idea of extending the concept of mentoring from individuals in or between institutions to international mentoring between institutions and even national organizations captured the imagination of the participants. ${ }^{14}$ Many other ideas about strategies for research capacity building are included in the supplement of proceedings. ${ }^{4}$ Practice-based research networks, which are growing rapidly around the world, can function as a research capacity-building strategy for communitybased physicians, as well as provide and a way of effectively disseminating research results. ${ }^{19}$

During the conference there was a sense that the developing countries could be marginalized by most of the ideas emerging from the discussions. On further reflection during the last day of the meeting, however, many of the ideas, especially about capacity building, were found relevant and useful for underdeveloped jurisdictions. The concept of a clearinghouse hosted by Wonca and examples of mentoring between developed and underdeveloped partners were found to be relevant for developing countries. ${ }^{20}$ Examples of how the application of simple epidemiological or research principles was feasible in "chaotic and overwhelmed" underdeveloped health care systems were inspiring. The concept of com- munity-oriented primary care has provided dramatic improvements in population health status in underserved populations. ${ }^{21-23}$

The conference participants departed, inspired by the richness of ideas that emerged from a unique international blending of minds, further convinced of the pressing need to strengthen research in family medicine in all the countries of the world. Improving the health status of the world's population will increase equity by assisting every human being to realize his or her full potential. Implementation of the 9 recommendations supported by the conference participants will require showing our physician colleagues and the world's governments the benefits of investing in family medicine research. Success in this strategy can improve the health of the world. Failure to increase investment will be to lose a great opportunity to make the world a better place for all inhabitants.

The meeting was sponsored by Wonca, Health Canada, the Canadian International Development Agency, Queens University and the Department of Family Medicine Center for Studies in Primary Care, the Department of Family Medicine at University Medical Center Nijmegen, the Dutch College of General Practitioners, the American Academy of Family Physicians, the College of Family Physicians Canada, the Royal Australian College of General Practitioners, and the North American Primary Care Research Group.

To read or post commentaries in response to this article, see it online at http://www.annfammed.org/cgi/content/full/2/suppl_2/S2.

Key words: Clinical research; family medicine; family practice, general practice; capacity building; international cooperation; world health

\section{References}

1. Institute of Medicine. Committee on Quality of Health Care in America. Crossing the Quality Chasm. A New Health System for the 21st Century. Washington, DC: National Academies Press; 2001.

2. Starfield B. Is primary care essential? Lancet. 1994;344:129-133

3. Green LA, Fryer GE, Yawn BP, Lanier D, Dovey SM. The ecology of medical care revisited. N Engl J Med. 2001;344:2021-2025

4. Van Weel C, Rosser W. Improving health globally: the necessity of family medicine research - a critical review of its implications and recommendations to build its capacity. Ann Fam Med. 2004;2:S5-S16.

5. Starfield, B. Primary Care: Balancing Health Needs, Services and Technology. New York, NY: Oxford University Press; 1998

6. Deconnick S, Boeke AJP, van der Waal I, et al. Incidence and management of oral conditions in general practice. $\mathrm{Br}$ J Gen Pract. 2003;53:130-133.

7. Koning S, van Suijlekom-Smit LW, Nouwen JL, et al. Fusidic acid cream in the treatment of impetigo in general practice: double blind randomised placebo controlled trial. BMJ. 2002;342:203-206.

8. Okkes IM, Oskam SK, Lamberts H. The probability of specific diagnoses for patients presenting with common symptoms to Dutch family physicians. J Fam Pract. 2002;51:31-36. 
9. Dutch College of General Practitioners [Nederlands Huisartsen Genootschap]. Practice guidelines English summary. Available at: http://nhg.artsennet.nl/content/resources/AMGATE_6059_104_TICH_ L93909649/AMGATE_6059_104_TICH_R1199541362500411//.

10. Guideline Advisory Committee, for the Ministry of Health and Long Term Care and the Ontario Medical Association. Recommended clinical practice guidelines. Available at: http://www.gacguidelines.ca.

11. De Melker RA. Diseases: the more common the less studied. Fam Pract. 1995; 12:84-87.

12. Sant'Ana AM, Rosser W, Talbot Y. Five years of health care in Sao Jose. Fam Pract. 2002;19:410-415.

13. Isaakidis $P$, Swingler GH, Piennaar EE, Volmink nJ, loannina JPA. Relations between burden of disease and randomized evidence in sub-Sahara Africa: survey of research. BMJ. 2002;324:702

14. Anonymous. Is primary-care research a lost cause? Lancet. 2003;361: 977.

15. Del Mar C, Askew D, Building family medicine research capacity. Ann Fam Med. 2004;2(Suppl 2):S35-S40.

16. Hutchinson A, Becker L. Styles and methods of family medicine: their impact on the research agenda. Ann Fam Med. 2004;2(Suppl 2): S41-S44.
17. Nutting PA, Beasley JW, Werner JJ. Asking and answering questions in practice: practice based research networks build the science base of family practice. JAMA. 1999;281:686-688

18. McWhinney IR. A Textbook of Family Medicine. 2nd ed. New York, NY, Oxford University Press; 1997:168

19. Green LA, Dovey SM. Practice-based primary care research networks. They work and are ready for full development and support. BMJ. 2001;322:567-568.

20. Sparks B, Gupta S. Research in family medicine in developing countries. Ann Fam Med. 2004;2:S5-S9.

21. Iliffe S, Lenihan P, Wallace P, Drennan V, Blanchard M, Harris A. Applying community-oriented primary care methods in British general practice: a case study. Br J Gen Pract. 2002;52:646-651.

22. Nutting PA, Wood M, Conner EM. Community oriented primary care in the United States: a status report. JAMA. 1985;253:17631766.

23. Kark SL, Kark E. An alternative strategy in community health care: community-oriented primary health care. Isr J Med Sci. 1983;19: 707-713

\section{Acknowledgments}

Publication of this supplement and organization of the conference in Kingston, Ontario, Canada, March 8 to 11, 2003, from which this material was derived, would not have been possible without contributions from many. First and foremost, our gratitude is with the academic primary care leaders who dedicated their precious time and talents to participate in the conference and to prepare or peer review the background material (see the list of participants).

Organization of the Kingston conference and preparation of this supplement depended to a large extent on the untiring support of Yvonne Chung at the Wonca Secretariat in Singapore; Vicky Garrah and Sonja Verbeek at the Centre for Studies in Primary Care, Queens University, Kingston, Ontario, Canada; and Caroline Roos at the Department of General Practice, University Medical Center, Nijmegen, the Netherlands. Their support is graciously acknowledged.

The World Organization of Family Doctors (Wonca) and the guest editors would like to acknowledge the following organizations for their generous financial support:

- Health Canada

- The Canadian International Development Agency (CIDI)

- Queens University, Kingston, Ontario, Canada

- The American Academy of Family Physicians (AAFP)

- The Royal Australian College of General Practitioners (RACGP)

- The College of Family Physicians of Canada (CFPC)

- The Netherlands College of General Practitioners (NHG)

- The North American Primary Care Research Group (NAPCRG)

- The Centre for Studies in Primary Care, Queens University, Kingston, Ontario, Canada

- The Department of General Practice, University Medical Center, Nijmegen, the Netherlands. 